\title{
IN SEARCH FOR BIOMARKERS, ENDOPHENOTYPES OR BIOSIGNATURES OF PTSD: WHAT HAVE WE LEARNED FROM THE SOUTH EAST EUROPEAN STUDY
}

\author{
Miro Jakovljevic \\ Department of Psychiatry and Psychological Medicine, University Hospital Centre Zagreb, Zagreb, Croatia
}

received: 18.6.2019;

revised: 14.7.2019;

accepted: 27.8.2019

\begin{abstract}
SUMMARY
Posttraumatic stress disorder (PTSD) is a complex mental disorder whose neurobiology, including epi/genetics, is still elusive. The South East European (SEE)-PTSD study has conducted an impressive amount of research on molecular mechanisms of PTSD. The results of the study make obvious the need of coordinated pluralism and transdisciplinary integrative approach in research on molecular mechanisms of PTSD and other stress-related disorders. The development of PTSD is influenced by a tangled and complicated interaction of inborn or acquired predisposition or vulnerability and environmental adversity which alters gene regulation producing effects on neurons and brain systems and inducing changes in cognition, emotion and behavior. There are still no identified objective biomarkers or tests which could confirm the trauma exposure or identify the real presence of PTSD. The puzzle how brain function enables the resilience to adversity and how brain dysfunctions lead to vulnerability to stress and development of PTSD and other stress-related disorders is still awaiting reliable explanation. Discovery of PTSD associated epi/genetic factors might provide reliable markers for pathogenesis, what could result in getting novel therapeutics and/or objective stratifying patients for research.
\end{abstract}

Key words: PTSD - biomarkers - epi/genetics - vulnerability - resilience

$* * * * *$

\section{INTRODUCTION}

Posttraumatic stress disorder (PTSD) is a complex mental disorder whose neurobiology including epi/genetics is still elusive. Although PTSD is one of the best defined mental disorders it has been surrounded with much scientific controversy and debate (Jakovljevic et al. 2012a). High variation in PTSD rates is a very challenging issue. PTSD is multidimensional and multiinterpretable phenomenon which can be depicted from various, but mutually complementary, theoretical, conceptual and research perspectives (Jakovljevic et al. 2012b, Jaksic et al. 2012). After surviving extreme stress and/or traumatic events many individuals speak about personal transformation that happened in them (see Yehuda et al. 2018). The transformation can be related to morbid and pathogenic or salutogenic (resilience, post-traumatic growth) mechanisms. Pathogenic mechanism cause anxiety disorders, depressive disorders, acute stress disorders, PTSD, post-traumatic embitterment disorder (PTED). Salutogenic and resilience mechanisms not only protect mental health and prevent stress-related mental disorders but they also may induce post-traumatic growth (PTG). Humans may respond to traumatic situations by trying to understand their adversity and by inventing compensations, corrections or advantages. PTG involves five components like personal mastery, new perspective and possibilities, self-transcendence and spiritual transformation, new meaning/purpose and appreciation of life and last but not least positive communication and relating to others (see also Wu et al. 2015). The puzzle of what influences the moving mind to act in an advantageous and resilient or disadvantageous and pathogenic manner is a great challenge in current medicine of stress, psychotraumatology and psychiatry. Understanding of molecular mechanisms and processes of psycho-traumatization and resilience, salutogenesis and pathogenesis of PTSD is closely associated with the search/pursuit for biomarkers, endophenotypes or biosignatures of PTSD. In this framework the South East European (SEE)-PTSD (Dzubur-Kulenovic et al. 2016, Deckert 2019) study has pointed to the need of coordinated pluralism and transdisciplinary integrative approach in research on molecular mechanisms of PTSD and other stressrelated disorders.

\section{PTSD AND PRECISION PSYCHIATRY}

The precision psychiatry, "an emerging approach for treatment and prevention that takes into account each person's variability in genes, environment, and lifestyle" (see del Buono 2018) is still a wishful thinking, although the necessary technology to put it into operation is currently available. Regarding stress-related disorders like PTSD precision psychiatry tends to use measurable health parameters or objective biomarkers to identify individuals at risk of a PTSD, to improve diagnostic punctuality and to offer a personalized (patient-tailored) therapy. Theoretically, it is expected that is possible to combine clinical data with different neurobiological measures, single-nucleotide 
polimorphisms and epigenetic mechanisms in the different populations of patients with PTSD in order to identify profiles that refers to and predict individual clinical response to individualized or personalized treatment as well as to predict reaction to adversity and prevent development of PTSD. In research there are three categories of biomarkers of PTSD: single markers, endophenotypes and biosignatures which may come from molecular genetics, biochemistry and neuroimaging. However, identifying endophenotypes, biomarkers and biosignatures that would be applicable and useful for prediction and précising clinical diagnosis of PTSD, monitoring illness regression and predicting treatment response is still wishful, but promising way of thinking. Endophenotypes are specific trait markers of an illness regardless of the phenotypic presence or absence of illness because they are heritable (Ozomaro et al. 2013). Biomarkers are measurable parameters that reflect biologic function or dysfunction, response to a treatment method, or predict the natural progression of illness. Because of the obvious polygenic nature of mental disorders, with thousands of genetic variants contributing to disease liability, lies one of the reasons why the search for isolated endophenotypes of psychiatric disorders has been less than fruitful; it seems endophenotypes, defined as quantitative neurobehavioral traits that index genetic susceptibility for a psychiatric disorder, are also transdiagnostic and could be used to develop insights into the nature of comorbidity and how genetic risk is shared across disorders or is specific to one (Iacono 2018). An attractive alternative to the single markers is the concept of biosignature as the biological equivalent of a patognomonic sign that could complement, augment, and make psychiatric diagnosis more valid and reliable. For the time being, the reported biomarkers do not index pathophysiology or treatment responses and do not enable prediction and treatment selection with regards to PTSD.

From a complex systems perspective PTSD and other stress-related mental disorders can be depicted in multiple different ways such as in terms of dysfunctional epigenetic mechanisms, dysfunctional neuronal circuits and brain systems, allostatic-homeostatic failure, post-trauma symptom-symptom network dynamics, brain miscomputations, misrepresentations and aberrant mentalizations, neurodevelopment disorders, toxic encephalopathy pathopsychodynamics and dysfunctional self-dynamics etc. Neurobiologically informed psychopathology" (Strik et al. 2017) or in other words functional psychopathology with a neuroscientific depiction of underlying neuronal networks and brain systems is essential to understand the mental functions, their regulation and dysregulation in PTSD. Epi/genetic, artificial intelligence and new technologies could deeply change our way of understanding of PTSD regarding at-risk individual's identification, early and precise diagnosis of PTSD, monitoring of PTSD and predicting outcome. The concept of a PTSD digital phenotype (Bourla et al. 2018) is a great challenge in current psychotraumatology. Putative epigenetic mechanisms in the transgenerational effects of trauma are particularly exciting issues (Yehuda et al. 2018, Youseff et al. 2018).

\section{PTSD BETWEEN RESILIENCE AND VULNERABILITY/WEAKNESS}

Human response to traumatic stress is one of the most challenging issues in psychotraumatology and psychiatry. Although the majority of humans in general population are exposed to traumas, only few of them, about $10 \%$ will develop PTSD, but the many depression and anxiety disorders. According to the vulnerabilityresilience model some individuals are more vulnerable while others are more resilient to mental distress. PTSD and positive mental health are two ends of a onedimensional continuum and they depend on a complex interaction of the three groups of factors: 1. ,risk“ or „vulnerability factors“ (personality weakness) which enhance the likelihood of PTSD and other stress-related disorders, 2. "protective factors" that enhance the likelihood of recovery from trauma and stress, and 3. „generative or creativity factors" which increase revelatory learning, resource acquisition and development, accentuating personal growth. Resilience may be defined as a collection of protective and salutogenic factors that modulate the relationship between a stressful event, adversity or disease, and positive outcomes. Resilience is about the whole person, it includes biological, psychological, social and spiritual dimension of human existence. It enables individuals and communities to survive and adapt to challenges and adversities but sometimes also to be better off and to grow and thrive (post-traumatic growth) in addition to overcoming a specific adversity. Resilience may involve positive psychological transformation and personal growth, an indivisible part of mental health and health in general, well-being and quality of life as well as recovery and treatment outcome. It is very important to note that some resilience factors may contribute to the development of other resilience factors, and, in consistency with a cascade model, together they contribute to predict personal recovery. Resilience enables people not only to successfully cope with extreme stress and traumatic events but also to recover from PTSD and other stress-related disorders or to live with PTSD in more meaningful and creative way. Primary resilience is related to maintaining equilibrium, balance and mental health as well as with the absence of posttraumatic symptoms. The level of primary resilience has been regarded as a protective factor against developing PTSD what means that lack of resilience carries a risk of its development. It can be described as "bouncing back" and "rebounding after adversity" and as such it is related to PTSD prevention. The concept of primary resilience explains why many people do not 
develop a PTSD or some other disorder although they are subject to the same kind of adversary events, even after a prolonged period of adversity, with psychological and physical burdens. (Jakovljevic \& Borovecki 2018). Resilience can coexist with PTSD (Rakesh et all 2019) so that secondary resilience refers to the capability of individuals to cope with PTSD and successfully recover. It is aimed to regain mental equilibrium and somatic balance after allostatic load and illness. The capability to achieve clinical, functional/social and personal recovery implies the presence of secondary resilience. In addition to clinical remission, secondary resilience may lead to personal growth and developing a meaningful life after PTSD. Tertiary resilience enables patients to develop a healthy and productive way to live with their PTSD, helps them to adapt to limitations in life associated with illness and have positive and creative life attitudes.

Although understanding resilience is very important for understanding, preventing and treating PTSD (see Horn \& Feder 2018) resilience as a research aim (see Mehta et al. 2018) and treatment target has been largely neglected. Resilience does not mean just the absence of PTSD. Some person can be highly resilient to some adversities, but very vulnerable to others. Big differences in psychopathology of individuals exposed to similar psychotrauma indicate a complex relationship between genes, environment and stress-related disorders. Each patient is unique, responsive and responsible person and within every person there is a force that drives them to strive to self-realization, self-understanding, self-transcendence, and a sense of coherence and control over their own life. Resilience is positively associated with PTG and both of them are essential salutogenic elements. Good news is that resilience and reflective instead of brooding rumination can be enhanced through learning and rational-emotional-behavioral training (REBT). Resilience training can result in augmented neuroplasticity and balance of neural circuits that modulate reward and motivation, emotion regulation, cognitive reappraisal and executive function, novelty seeking, harm avoidance and fear response, selfdirectedness, cooperativeness and adaptive social behavior, and self-transcendence. Mental vulnerability and personal weakness is associated with vicious circles while resilience involves creating of virtuous cycles.

\section{PTSD between vicious and virtuous cycles}

Circular feedback model (CFM) of mental disorders is a concept based on neuroscience, cognitive psychology, information processing which emphasize the circular and biopsychosocial nature of stress-related disorders as well as the role of multiple factors that can trigger, exacerbate, or maintain PTSD, depression and anxiety (Alladin 2007). Furthermore, PTSD increases also possibility of developing various somatic illnesses so that patients with PTSD have a higher mortality from multiple causes compared with normal population (see
Jaksic et al. 2015, Sagud et al. 2018). From the systems perspective, any mental disorder is part of the feedback process, not existing apart from it. There are two types of feedback processes: reinforcing and balancing (Senge 2006). Whenever things are growing, reinforcing or amplifying is at work. Two types of reinforcing feedback processes can be recognized: the one that forms „vicious“ cycles and the other „virtuous“ cycles. Some reinforcing processes in stress-related mental disorders are ,vicious cycles“, in which processes start off badly and grow worse (the cuckoo's egg syndrome). Vicious and virtuous cycles, PTSD and PTG are predicated on rumination and resilience. Rumination is depicted as the repetitive passive and self-focused responses to the extreme stress or traumatic event that focus on traumatic symptoms, their causes and consequences (Aladin 2007, Wu et al. 2015). Rumination and negative mood with lack of attention and impaired decision making in major depressive disorder can be depicted as "strong attractor states in emotion and self-referential processing systems" related to "two network hubs with strong self-excitation but mutual inhibition" and when "either increasing the amount of self-excitation in one of two hubs or through an imbalance in the feedback between the two, one of the two attractor basins strongly expand at the expanse of the other" (Durstewitz et al. 2018). According to some authors there are three different types of rumination: brooding, reflection and depression-related rumination (see $\mathrm{Wu}$ et al. 2015). Brooding rumination refers to a repetitive, intrusive and passive consideration of traumatic experience or negative emotions comparing the present situation with unachieved possibilities while reflective rumination represents a good and protective form of rumination promoting the positive life changes after traumatic experience and salutogenic effects (see $\mathrm{Wu}$ et al. 2015). Depression-related rumination is underlying mechanism of major depressive disorders and depression-related vicious cycles. In fact, depression can be depicted as a vicious circle of negative affectivity, cognition and behavior related to the negative cognitive triad about self (negative self-precept), world (hostile and demanding) and future (the expectation of suffering and failure). The comorbidity between PTSD and depression is well known fact. Brooding rumination and depression-related rumination are positively related to PTSD symptoms and distress while PTG is associated with reflective rumination (see $\mathrm{Wu}$ et al. 2015). Personal, psychological and spiritual posttraumatic growth is strongly associated with processes that reinforce reflective rumination in desired directions of virtuous cycles. Balancing processes are associated with discovering the sources of stability and resistance (Senge 2006). Balancing processes underlies all goal-oriented behavior. Human mind-body system contains countless of balancing feedback processes that may heal our traumas and alert us to real threat. Organizations and societies have also myriad balancing feedback processes which may support healing, 
recovery and resilience. The healing process and recovery are always balancing processes. The recovery occurs when a new balance between resilience from one side and damage and vulnerability from another side establishes enriching victim's mission, purpose and quality of life. The road to full recovery is grounded not exclusively in alleviating the negative, but also in fostering the positive processes in a system. Bringing the person out of suffering and negative functioning is one form of success, but facilitating progression toward the restoration of positive functioning is also very important (Cloninger 2004).

\section{PTSD AS DISORDER OF NEURONAL NETWORK COALITION AND CAUSALLY INTERACTING SYMPTOMS}

A network theory of PTSD may be articulated in two forms: 1. in clinical psychopathology as a syndrome constellation of symptoms that hang together empirically, and which can cause each other; 2. in neuroscience as concept that PTSD reflects aberrant or dysfunctional brain networks. The systems approach network neuroscience and network theory integrate many insights in PTSD from different paradigms and perspectives.

According to the network approach to psychopathology PTSD can be depicted as complex networks states of causally interacting symptoms because stressrelated disorders follow network structure in which some symptoms are more firmly connected than others (Borsboom 2017, Borsboom et al. 2019). Symptoms of PTSD occur together not only because they reflect a common underlying mechanism, but also they influence each other. In other words symptoms may have common causes, to be a result of individual developmental trajectories or of environmental adversity, but also they can cause one another forming a cascade of causal, vicious relationships. The coupled sets of symptoms that are close in the network will tend to synchronize and form a self-sustaining cluster of symptoms and conditions (Borsboom 2017). This concept explains hysteresis effect, the self-sustaining symptom network that keeps itself activated even when precipitating causes have disappeared (Borsboom et al. 2019). The formation of trauma memories is very distressing from one side, but from the other side it is adaptive and may contribute to personal growth and survival. However, in the states of insufficient glucocorticoid signaling, deficits in fear conditioning with hypersensitivity and insufficient extinction learning it could result in a cascade of maladaptive PTSD symptoms (see Yehuda et all. 2015). Systems network theory offers valid possibility for data integration from symptoms networks and brain circuits networks studies. As modern network science may provide an explicit study of billions relationships in a single network model, it may enable a new noso- logy for clinical psychiatry that emphasizes the relationship between symptoms and syndromes and does not presume artificial separation between them (Goekoop \& Goekoop 2014).

From recent time the complex brain network characteristics in health and illness have become objects of mathematical deciphering. Major mental disorders reflect deficits in access, engagement and disengagement of large scale brain networks as well as disrupted information processing due to damage or dysfunction of individual nodes or edges. As according to dynamical systems theory (DST) the mental functions and processes are implemented in terms of the neural dynamics, mental illnesses may be viewed as disorders of neural network dynamics which involve alterations of oscillations, synchronization among units of a system, attractor states, phase transitions, or deterministic chaos" (Durstewitz et al. 2018). There are four recognizable contexts in current computational psychiatry that can be applied to PTSD: 1. Dysfunctional brain connectivity; 2. Dysfunctional network dynamics; 3. Misrepresentation; and 4. Aberrant information processing involving inference, information integration and choice. Neurons make up intrinsically coherent neural networks that perform many brain functions, but neural networks also interconnect into more complex networks enabling development of higher mental functions and complex learning and behaviors. Mental functions are represented by the joint activation of groups of neurons which form networks or assemblies by strengthening connection between neurons that fire together commonly and persistently. The brain systems or networks identified in literature as central executive system/network, memory formation \& recollection system, default-mode system, central security (alarm) or harm avoidance system, approach-avoidance system, sleep-wakefulness (vigilance/alertness) system, motivational/reward-punishment system, decision-making system, appraisal-reappraisal/salience (trust-distrust) system, dominance-submission system, separation-attachment system, appetitive-aversive system, novelty seeking/ epistemic system, habituation-sensitization (learning) system, empathy/mirror neuron system are very important functional neuroscience-based psychopathology. Alterations of the brain networks in the connectome (a large-scale brain network) have been reported in many major mental disorders including PTSD indicating on biomarkers for illness diagnosis and prognosis as well as for evaluation of treatment effectiveness (Cao et al. 2015). Biological response, involving both vulnerability and resilience, to stress is related to the complex interaction between several different neuronal networks or brain systems. Fluctuations in the activity and alterations of the functional connectivity of the default mode network, the salience (appraisal-reappraisal) network and the central executive network may explain shift into dramatically different states in patients with PTSD (see Yehuda et al. 2015). 


\section{MOLECULAR MECHANISMS OF PTSD: THE SOUTH EAST EUROPEAN STUDY}

The South East European (SEE)-PTSD study has conducted an impressive amount of research on molecular mechanisms of posttraumatic stress disorder (PTSD). Within this scientific framework, psychiatrists from several countries affected by the wars in former Yugoslavia during the 1990s have developed collaboration with psychiatric and genetic experts from Wuerzburg, Germany. The rationale, design and methods of the SEE-PTSD study were described in detail elsewhere (see Dzubur-Kulenovic et al. 2016). Recently, the journal Psychiatria Danubina, in the spirit of promoting scientific projects and collaboration in the Danube region countries, has published 9 original research papers based on the findings obtained within the SEE-PTSD study (Kravic et al. 2019, Kucukalic et al. 2019, Feric Bojic et al. 2019, Muminovic Umihanic et al. 2019, Haxhibeqiri V. et al. 2019, Haxhibeqiri S. et al. 2019, Goci Uka et al. 2019, Hoxha et al. 2019, Jaksic et al. 2019). These articles have investigated the associations between PTSD, defined in terms of diagnostic categories as well as dimensional symptom severities, and various individual candidate genes. These 19 genes include those of monoaminergic transmission (SLC6A4, MAO-A, COMT, TPH2, SLC6A3, HTR1A, DRD2, and DRD4), other neurotransmission systems (GAD1, NPSR1, CNR1, NPY, and OXTR), HPA-axis (CRHR1, FKBP5), growth factor and immunomodulatory genes $(B D N F, I L-6)$, and other genes known to be related to PTSD (RORA, MBP). The results of SEE-PTSD study confirmed the claim of Yehuda et al. (2015) that there are still no identified objective biomarkers or tests which could confirm the trauma exposure or identify the real presence of PTSD. Generally speaking, in genetics there have been a lot of attempts to identify genes that might predispose some people to develop certain illnesses including PTSD. This approach is based on mechanicistic concept that there is a gene for everything. In reality it is entirely plausible that different gene combinations are associated with specific illness in a way that is too complex for a human to research and understand. The findings of the SEE-PTSD study showed that neither of the associations between variations in gene polymorphisms and categorical and/or dimensional measures of PTSD and general psychiatric distress, remained significant after implementing more stringent statistical criteria (i.e., correction for multiple testing). Overall, candidate gene studies of PTSD have been underpowered, thus making many positive and negative results and findings difficult to interpret. Nominally significant genetic associations in PTSD were documented, however, none of the associations remained significant after the statistical correction for multiple testing. More specifically, only three genes were nominally related to the categorical diagnosis of
PTSD (GAD1, NPSR1, FKBP5), while more of them were nominally associated with dimensional symptom severity of PTSD (MAO-A, OXTR, NPY, IL-6, FKBP5) and/or general psychiatric distress (RORA, NPY, COMT, IL-6, NPSR1, HTR1A, DRD2). The fact that most of these genetic associations were found for dimensional measure of PTSD and, particularly, broader psychiatric symptomatics, is in line with emerging conceptualizations of mental disorders. Namely, each mental disorder is best understood as a combination of diagnosis-specific features and a transdiagnostic factor reflecting general psychopathology (Lahey et al. 2014, McGorry \& Nelson 2016), supported even by recent neuroanatomical findings in various psychiatric populations, including patients with PTSD (Gong et al. 2019). Consistent with this notion, an increasing number of genetic and epidemiological studies are pointing to large overlap between different psychiatric disorders. Similar sets of genes and environmental risk factors have been found to underlie a range of diagnostic categories, including schizophrenia, depression, obsessive-compulsive disorder (OCD), and (warrelated) PTSD (see Smoller 2016, Blocker et al. 2019). It is not to be expected that a single biomarker can impact the diagnosis and treatment of any mental illness. Possible solution to this problem has been developed in area of machine learning and using combination of predictors for nonlinear systems. In machine learning and Big Data there is a very useful idea that unifying several weak classifiers which predict barely better than guessing can produce a strong classifier. Brain is a complex system and in complex systems, by definition, every variable is influenced my multitude of other variables. The more causal factors there are the less variance each individual factor can explain. Thus it is unlikely that behavior and psychological processes can be adequately explained by handful of variables. Instead of using individual markers research paradigm needs to switch to using marker composites created by machine learning methods which is related to the first idea that task of deriving biomedical markers should be relegated to artificial intelligence. Scientist should then strive to reverse engineer the markers created by AI and generate theoretical knowledge about brain and mental functioning. This approach requires large amount of data both in terms of patients and number of different measurements such as brain imaging or genetic testing which can be economically challenging. For that reason researchers need to collaborate with practitioners and work on creating large, shared datasets so field as a whole can truly reap the benefits of Big Data revolution. The story of endophenotypes and epi/genetics of PTSD is very complex one so that we need machine learning to analyse huge amount of data from cohort of individuals monitored longitudinally for patho/physiologic parameters, epigenetic modulators, personal (prenatal stress, childhood trauma exposure, and transgenerational 
trauma history, personality profiles and environment characteristics (see also Rakesh et al. 2019). Only combination of multiple specific biomarkers obtained by multiomics or panomics can identify aetiology, diagnostics and prognostics of mental disorders. Transdisciplinary systems approach that integrates many diverse inputs including neurobiological, phenomenological, environmental and clinical information may produce plausible specific models for individual mental disorders.

\section{CONCLUSIONS}

PTSD is predicated on the polygenic architecture with complex combinations of interacting epi/genetic mechanisms. Discovery of PTSD associated epi/genetic factors might provide markers for pathogenesis, what could result in defining molecular targets for drug discovery and getting novel therapeutics as well as enable objective stratifying patients for research. In the future research PTSD should be distinguished both categorically sybtypes (hyperarousal subtype, dissociative subtype, etc.) and dimensionally in relation to genetic/epigenetic stratification. In contrast to classical methods of candidate-gene studies, only integrative, genome-wide approaches analysing gene networks could disentangle complex endophenotypes - genetic/ epigenetic - environment architecture and biological background of PTSD and other stress-related disorders. There is a great expectation from macnine learning and whole-exome sequencing which may analyse the coding regions of thousand genes.

\section{Acknowledgements: None.}

\section{Conflict of interest: None to declare.}

\section{References}

1. Alladin A: Handbook of Cognitive Hypnotherapy for Depression - An Evidence-Based Approach. Wolters Kluwer/ Lippincott Williams \& Wilkins, Philadelphia, 2007

2. Blacker CJ, Frye MA,Morava E, Kozicz $T$ \& Veldic M: A review of epigenetics of PTSD in comorbid psychiatric conditions. Genes 2019; 10:140. doi:10.3390/genes 10020140

3. Borsboom D, Cramer AOJ \& Kalis A: Brain disorders? Not really: Why network structures block reductionism in psychopathology research. Behavioral and Brain Sciences 2019; 42, e2:1-63 doi:10.1017/50140525X17002266

4. Borsboom D: A network theory of mental disorders. World Psychiatry 2017; 16:5-13

5. Bourla A, Mouchabac S, El Hage $W$ \& Ferreri F: ePTSD: An overview on how new technologies can improve prediction NS ssessment of Posttraumatic Stress Disorder (PTSD). European Journal of Psychotraumatology 2018; 9:1424448

htps://doi.org/10-1080/20008198.2018-1424448
6. Cao M, Wang $Z$ \& He Y: Connectomics in psychiatric research: advances and applications. Neuropsychiatric Disease and Treatment 2015; 11:2801-2810

7. Cloninger CR: Feeling Good: The Science of Well-Being. Oxford University Press, 2004

8. Deckert J: The South-East European (SEE)-PTSD Study. Psychiatria Danubina 2019; 31:210

9. Del Buono G: The precision psychiatry: An individualized approach to the disease. Psychiatr Danub 2018; 30(suppl 7); 436-438.

10. Dzubur-Kulenovic A, Agani F, Avdibegovic E, Jakovljevic M, Babic D, Kucukalic A, Kucukalic S, Dzananovic ES, Mehmedbasic AB, Uka AG, Haxhibeqiri S, Haxhibeqiri $V$, Hoxha B, Sinanovic O, Kravic N, Muminovic M, AukstMargetic B, Jaksic N, Franc AC, Rudan D, Pavlovic M, Babic R, Bojic EF, Marjanovic D, Bozina N, Ziegler C, Wolf $C$, Warrings B, Domschke $K \&$ Deckert J: Molecular mechanisms of posttraumatic stress disorder (PTSD) as a basis for individualized and personalized therapy: rationale, design and methods of the South Eastern Europe (SEE) - PTSD Study. Psychiatr Danub 2016; 28:154-63

11. Durstewitz D, Huys QJM \& Koppe G: Psychiatric illnesses as disorders of network dynamics. Transcontinental Computational Psychiatry Workgroup 2018 doi: https://arxiv.org/pdf/1809.06303.pdf

12. Ferić Bojić E, Kučukalić S, Džubur Kulenović A, Avdibegović E, Babić D, Agani F, Jakovljević M, Kučukalić A, Bravo Mehmedbašić A, Šabić Džananović E, Kravic N, Babić R, Pavlović M, Aukst Margetic B, Jaksic N, Cima Franc A, Rudan D, Haxhibeqiri S, Goci Uka A, Hoxha B, Haxhibeqiri $V$, Muminović Umihanić $M$, Sinanović $O$, Božina B, Ziegler C, Wolf C, Warrings B, Domschke K, Deckert $J \&$ Marjanović D: Associations of gene variations in neuropeptide $Y$ and brain derived neurotrophic factor genes with posttraumatic stress disorder. Psychiatr Danub 2019; 31:227-34

13. Goçi Uka A, Agani F, Blyta A, Hoxha B, Haxhibeqireceptor $1 A$ (HTR1A) and tryptophan hydroxylase 2 (TPH2) genes in the development of PTSDri S, Haxhibeqiri V, Sabic Dzananovic E, Kucukalic $S$, Bravo Mehmedbasic A, Kucukalic A, Dzubur-Kulenovic A, Feric Bojic E, Marjanovic D, Kravic N, Avdibegovic E, Muminovic Umihanic M, Jaksic N, Cima Franc A, Rudan D, Jakovljevic M, Babic R, Pavlovic M, Babic D, Aukst Margetic B, Bozina N, Sinanovic O, Ziegler C, Warrings B, Domschke K, Deckert $J \&$ Wolf C: Role of the allelic variation in the 5-hydroxytryptamine. Psychiatr Danub 2019; 31:256-62

14. Goekoop R \& Goekoop JG; A network view on psychiatric disorders: Network clusters of symptoms as elementary syndromes of psychopathology. PLoS ONE 2014; 9 (11): e112734. doi: 10.1371/journal.pone.0112734

15. Gong Q, Scarpazza C, Dai J, et al. A transdiagnostic neuroanatomical signature of psychiatric illness. Neuropsychopharmacology. 2019;44(5):869-875.

16. Haxhibeqiri S, Haxhibeqiri V, Agani F, Goci Uka A, Hoxha B, Dzubur Kulenovic A, Kučukalić A, Avdibegović E, Sinanović O, Babic D, Jakovljevic M, Kučukalić S, Bravo Mehmedbašić A, Kravić N, Muminović-Umihanić M, Babić R, Pavlović M, Jakšić N, Aukst Margetić B, Rudan D, Ferić Bojić E, Marjanović D, Ziegler C, Wolf C, Warrings B, Domschke $K \&$ Deckert J: Association of neuropeptide $S$ receptor 1 and glutamate decarboxylase 1 gene polymorphisms with posttraumatic stress disorder. Psychiatr Danub 2019; 31:249-55 
17. Haxhibeqiri V, Haxhibeqiri S, Topciu-Shufta V, Agani F, Goci Uka A, Hoxha B, Dzubur Kulenovic A, Jakovljević M, Avdibegović E, Kravić N, Muminović Umihanić M, Sinanović O, Šabić Džananović E, Kučukalić A, Kučukalić S, Bravo Mehmedbašić A, Aukst Margetić B, Jakšić N, Cima Franc A, Rudan D, Pavlović M, Babić R, Ferić Bojić E, Marjanović D, Božina N, Ziegler C, Wolf C, Domschke $K$, Deckert $J$ \& Babic $D$ : The association of catechol-Omethyl-transferase and interleukin 6 gene polymorphisms with posttraumatic stress disorder. Psychiatr Danub 2019; 31:241-8

18. Horn SR \& Feder A: Understanding resilience and preventing and treating PTSD. Harward Review of Psychiatry 2018; 26:158-174

www.harwardreviewofpsychiatry.org

19. Hoxha B, Goçi Uka A, Agani F, Haxhibeqiri S, Haxhibeqiri V, Sabic Dzananovic E, Kucukalic S, Bravo Mehmedbasic A, Kucukalic A, Dzubur Kulenovic A, Feric Bojic E, Marjanovic D, Kravic $N$, Avdibegovic E, Muminovic Umihanic M, Jaksic N, Cima Franc A, Rudan D, Jakovljevic M, Babic R, Pavlovic M, Babic D, Aukst Margetic B, Bozina N, Sinanovic O, Ziegler C, Warrings $B$, Domschke K, Deckert J, Wolf C\& Vyshka G: The role of TAQIDRD2 (RS1800497) and DRD4VNTR polymorphisms in posttraumatic stress disorder (PTSD). Psychiatr Danub 2019; 31:263-8

20. Iacono WG: Endophenotypes in psychiatric disease: prospects and challenges. Genome Med 2018; 10:11. Published $2018 \mathrm{Feb} 22$

21. Jakovljevic $M$ \& Borovecki F: Epigenetics, resilience comorbidity and treatment outcome. Psychiatr Danub 2018: 30:242-253 https://doi.org/10.24869/psyd.2018.242

22. Jakovljevic M, Brajkovic L, Jaksic N, Loncar M, AukstMargetic $B$ \& Lasic D: Postraumatic stress disorders (PTSD) from different perspectives: A transdisciplinary integrative approach. Psychiatr Danub 2012; 24:246-255

23. Jakovljevic $M$, Brajkovic L, Loncar $M \&$ Cima A: Postraumatic stress disorders (PTSD) between fallacy and facts: What we know and what we don't know? Psychiatr Danub 2012; 24:241-245

24. Jakšić N, Aukst-Margetić B, Marcinko D, Brajkovic L, Loncar $M \&$ Jakovljevic M: Temperament, character, and suicidality among croatian war veterans with posttraumatic stress disorder. Psychiatr Danub 2015; 27:60-63

25. Jaksic N, Brajkovic L, Ivezic E, Topic R \& Jakovljevic M: The role of personality traits in posttraumatic stress disorder (PTSD). Psychiatr Danub 2012; 24:256-266

26. Jaksic N, Šabić Džananović E, Aukst Margetic B, Rudan D, Cima Franc A, Bozina N, Ferić Bojić E, Kučukalić S, Džubur Kulenović A, Marjanović D, Avdibegović E, Babić D, Agani F, Kučukalić A, Bravo Mehmedbašić A, Kravic $N$, Muminović Umihanić $M$, Sinanović $O$, Babić $R$, Pavlović M, Haxhibeqiri S, Goci Uka A, Hoxha B, Haxhibeqiri V, Ziegler C, Wolf C, Warrings B, Domschke $K$, Deckert $J$ \& Jakovljevic $M$ : A candidate gene association study of FKBP5 and CRHR1 polymorphism in relation to war-related posttraumatic stress disorders. Psychiatr Danub 2019; 31:269-75

27. Kravić N, Šabić Džananović E, Muminović Umihanić M, Džubur Kulenović A, Sinanović O, Jakovljević M, Babić $D$, Kučukalić A, Agani $F$, Kučukalić $S$, Bravo Mehmedbašić A, Goci Uka A, Haxhibeqiri S, Haxhibeqiri V, Hoxha B, Aukst Margetić B, Jakšić N, Cima Franc A, Rudan D, Pavlović M, Babić R, Ferić Bojić E, Marjanović
D, Božina N, Ziegler C, Wolf C, Warrings B, Domschke K, Deckert $J$ \& Avdibegović E: Association analysis of MAOA and SLC6A4 gene variation in South East European war related posttraumatic stress disorder. Psychiatr Danub 2019; 31:211-8

28. Kučukalić S, Ferić Bojić E, Babić R, Avdibegović E, Babić D, Agani F, Jakovljević M, Kučukalić A, Bravo Mehmedbašić A, Šabić Džananović E, Marjanović D, Kravic N, Pavlović M, Aukst Margetic B, Jaksic N, Cima Franc A, Rudan D, Haxhibeqiri S, Goci Uka A, Hoxha B, Haxhibeqiri V, Muminović Umihanić M, Sinanović $O$, Božina N, Ziegler C, Wolf C, Warrings B, Domschke K, Deckert J \& Džubur Kulenović A: Genetic susceptibility to posttraumatic stress disorder: analyses of the oxytocin receptor, retinoic acid receptor-related orphan receptor $A$ and cannabinoid receptor 1 genes. Psychiatr Danub 2019; 31:219-26

29. Lahey BB, Zald DH, Hakes JK, Krueger RF, Rathouz PJ. Patterns of heterotypic continuity associated with the cross-sectional correlational structure of prevalent mental disorders in adults. JAMA Psychiatry. 2014;71:989-96.

30. McGorry P, Nelson B. Why we need a transdiagnostic staging approach to emerging psychopathology, early diagnosis, and treatment. JAMA Psychiatry 2016; 73:191-2

31. Mehta D, Bruenig D, Lawford B, Harvey W, Carrillo-Roa T, Morris CP, Jovanovic T, McD. Young R, Binder EB \& Voisey J: Accelerated DNA methy lation aging and increased resilience in veterans: The biological cost for soldiering on. Neurobiology of Stress 2018; 8:112-119 www.elsevier.com/locatelynstr

32. Muminovic Umihanic M, Babic R, Kravic N, Avdibegovic E, Dzubur Kulenovic A, Agani F, Jakovljevic M, Babic D, Kucukalic A, Kucukalic S, Sabic Dzananovic E, Bravo Mehmedbasic A, Goci Uka A, Haxhibeqiri S, Hoxha B, Haxhibeqiri V, Aukst Margetic B, Jaksic N, Cima Franc A, Rudan D, Pavlović M, Feric Bojic E, Marjanovic D, Bozina N, Ziegler C, Wolf C, Warrings B, Domschke K, Deckert $J$ \& Sinanovic O: Associations between polymorphisms in the solute carrier family 6 member 3 and the myelin basic protein gene and posttraumatic stress disorder. Psychiatr Danub 2019; 31:235-40

33. Ozomaro U, Wahlestedt $C$ \& Nemeroff $C B$ : Personalized medicine in psychiatry: problems and promises. BMC Medicine 2013; 11:132 http://.www.biomedcentral.com/1741-7015/11/132

34. Rakesh G, Morey RA, Zannas AS, Malik Z, Marx CE, Clausen AN, Kritzer MD \& Szabo ST: Resilience as translational endpoint in the treatment of PTSD. Molecular Psychiatry 2019. https://doi.org/10.1038/s41380-019-0383-7

35. Sagud M, Jaksic N, Vuksan-Cusa B, Loncar M, Loncar I, Mihaljevic Peles A, Milicic D, Jakovljevic M: Cardiovascular disease risk factors in patients with posttraumatic stress disorder (PTSD): A narrative review. Psychiatr Danub 2017; 29:421-430

36. Senge PM: The Fifth Discipline: The Art and Practice of the Learning Organisation. Random House, London, 2006

37. Smoller JW: The Genetics of Stress-Related Disorders: PTSD, Depression, and Anxiety Disorders. Neuropsychopharmacology 2016; 41:297-319. doi:10.1038/npp.2015.266

38. Strik W, Stegmayer K, Wačlther $S$ \& Dierks T: Systems Neuroscience of Psychosis: Mapping schizophrenia symptoms onto brain systems. Neuropsychobiology 2017; 75:100-116 doi:10.1159/000485221 
39. Wu K, Zhang Y, Liu Z, Zhou P \& Wei C: Coexistence and different determinants of posttraumatic stress disorder and posttraumatic growth among Chinese survivors after earth quake: role of resilience and rumination. Frontiers in Psychology 2015; 6:1043 doi: 10.3389/fpsyg.2015.01043

40. Yehuda R, Hoge CW, McFarlane AC, Vermetten E, Lanius RA, Nivergelt CM, Hobfoll SE, Koenen KC, Neylan TC \& Hyman SE: Post-traumatic stress disorder. Nature Reviews (Disease Primers) 2015; 1:1-22 ww.nature.com/nrdp
41. Yehuda R, Lehrner A \& Bierer LM: The public reception of putative epigenetic mechanisms in the transgenerational effects of trauma. Environmental Epigenetics 2018; 1-7 doi:10.1093/eep/dvy018

42. Youseff NA, Lockwood L, Su S, H G \& Rutten BPF: The effects of trauma, with or without PTSD, and transgenerational DNA methylation alterations in human off-springs. Brain Sci. 2018; 8, 83; doi:10.3390/brainsci8050083
Correspondence:

Professor Miro Jakovljevic, MD, PhD

Department of Psychiatry and Psychological Medicine,

University Hospital Centre Zagreb

Kišpatićeva 12, 10000 Zagreb, Croatia

E-mail: psychiatry@kbc-zagreb.hr 